\title{
Perkembangan Pelabuhan Perikanan Prigi dan Dampaknya terhadap Kehidupan Sosial Ekonomi Nelayan Desa Tasikmadu, Kabupaten Trenggalek, 1978-2004
}

\author{
Khoirun Nikmah, Sutejo K. Widodo, Alamsyah \\ Program Magister Ilmu Sejarah, Fakultas Ilmu Budaya, Universitas Diponegoro
}

Alamat korespondensi: kanimarurun@gmail.com

\begin{abstract}
This article aims to analyze the development of Prigi Fishing Port and its impact on the socio-economic of fishermen community atTasikmadu Village, Trenggalek during the period 1978-2004. The Prigi Fishing Port experienced a stage of development from the Fish Landing Base (PPI) in 1978 to the Coastal Fisheries Port (PPP) in 1982, and then it was upgraded become the Nusantara Fisheries Port (PPN). The inauguration of Prigi holds in 2004. The impact of the port development affected in the socio-economic life of the coastal society in Tasikmadu. Social implications including on changes in fishing technology, work relations, and fishing catches. Meanwhile, economic impacts including changes in fishermen's income, employment, and the emergence of works opportunities.
\end{abstract}

Kaywords: Fishing Port; Coastal Society; Economic Income.

Diterima/ Received: 26 Juni 2018

Disetujui / Accepted: 2 Desember 2018

\begin{abstract}
Abstrak
Artikel ini bertujuan untuk menganalisis perkembangan Pelabuhan Perikanan Prigi beserta dampaknya terhadap kehidupan sosial ekonomi nelayan Desa Tasikmadu Kecamatan Watulimo, Kabupaten Trenggalek tahun 1978-2004. Pelabuhan Perikanan Prigi mengalami beberapa tahapan perkembangan. Pada mulanya, sebelum 1978, Pelabuhan Perikanan Prigi adalah Pusat Pendaratan Ikan (PPI), kemudian menjadi Pelabuhan Perikanan Pantai (PPP) pada 1982, dan pada 2001 ditingkatkan statusnya sebagai Pelabuhan Perikanan Nusantara (PPN). PPN Prigi yang diresmikan pada 2004 ini kemudian berdampak terhadap kehidupan sosial ekonomi nelayan Desa Tasikmadu. Dampak sosial perkembangan PPN Prigi meliputi perubahan teknologi penangkapan ikan, hubungan kerja, dan sistem pembagian hasil tangkap. Sementara, dampak ekonomi yang dialami oleh masyarakat setempat adalah perubahan pendapatan nelayan, penyerapan tenaga kerja, dan munculnya peluang usaha baru.
\end{abstract}

Kata Kunci: Pelabuhan Perikanan; Masyarakat Pesisir; Pendapatan Ekonomi.

\section{Pendahuluan}

Kabupaten Trenggalek terletak di Pesisir Selatan Jawa Timur. Kabupaten ini mempunyai teluk tersebar, yang disebut Teluk Prigi. Pada 1970-an, Teluk Prigi dimanfaatkan oleh penduduk yang bermata pencaharian sebagai nelayan. Pada saat itu, penangkapan ikan di pantai masih dilakukan dengan cara yang sederhana, salah satunya dengan menggunakan jaring yang ditarik oleh puluhan nelayan. Teluk Prigi memiliki keunikan tersendiri untuk diteliti, terlebih karena di sana, terdapat sebuah pelabuhan perikanan pantai, yang tidak lain adalah PPP Prigi. Dilihat dari aspek akademis, keberadaan PPP Prigi belum dikaji secara historis. Adapun beberapa kajian tentang masyarakat Teluk Prigi sebagian besar hanya memuat aspek ilmu perikanan, kelautan, dan sosiologi. Misalnya kajian sosial ekonomi masyarakat nelayan Prigi yang dilakukan Ratnawati dan Sutopo (2014) lebih menekankan pada 
model pengembangan dan pemberdayaan masyarakat pesisir melalui strategi pemasaran komoditas perikanan. Selain itu, kajian yang dilakukan oleh Pudji et.al (2017) hanya berfokus pada analisis ekonomi rumah tangga masyarakat nelayan di sekitar PPN Prigi yang ternyata juga dipengaruhi adanya tumbuhan bakau di sekitar Teluk Prigi. Namun demikian, kajian ini lebih menitikberatkan pada faktor yang memengaruhi perkembangan aktivitas sosial ekonomi masyarakat nelayan di sekitar PPN Prigi dari 1978-2004.

PPP Prigi terletak di Desa Tasikmadu, Kecamatan Watulimo, Kabupaten Trenggalek. Pelabuhan ini dibangun pada tahun anggaran 1978-1979 dan selesai pada tahun anggaran 1983-1984. Pembangunan PPP Prigi mendapat bantuan dari Pemerintah Daerah Tingkat I Jawa Timur serta Tingkat II Trenggalek. Bantuan diberikan berupa pemberian subsidi modal dasar untuk penyelenggaraan pelelangan ikan. Pada 1982, setelah PPP Prigi diresmikan, teknologi penangkapan ikan semakin berkembang (Dinas Kelautan dan Perikanan Kabupaten Trenggalek, 1983, p. 1).

Pada 2001, PPP Prigi ditingkatkan statusnya menjadi Pelabuhan Perikanan Nusantara (PPN) Prigi. PN Prigi diresmikan oleh Presiden Megawati Soekarno Putri pada 22 Agustus 2004. Berdasar latar belakang tersebut, kemudian muncul beberapa pertanyaan, yaitu: (1) Bagaimana perkembangan Pelabuhan Prigi dari PPI menjadi PPP sampai akhirnya menjadi PPN? (2) Bagaimana dampak perkembangan Pelabuhan Prigi terhadap kehidupan sosial-ekonomi nelayan Desa Tasikmadu, Kecamatan Watulimo, Kabupaten Trenggalek?

\section{Metode}

Penelitian ini merupakan penelitian sejarah maritim. Sejarah maritim meneliti masalah-masalah tentang masyarakat pantai, perkembangan pelabuhan, hubungan tingkat produksi, sektor jasa, dan sebagainya (Widodo, 2005, p. 8). Penelitian ini menggunakan sejumlah sumber dalam rentang waktu 1978-2004. Sumber yang digunakan terdiri atas sumber primer dan sumber sekunder. Sumber primer menggunakan arsip Pelabuhan Perikanan Prigi dari tahun 1982-2007, data statistik mengenai profil Kabupaten Trenggalek pada 2000 yang diperoleh dari BPS, serta arsip dari Dinas Perikanan dan Kelautan Kabupaten Trenggalek tahun 2002-2003. Sumber sekunder yang digunakan dalam studi ini adalah buku-buku yang membahas tentang Pelabuhan Prigi dan masyarakatnya.

Sumber-sumber yang telah didapat kemudian dianalisis melalui metode sejarah dan dibantu dengan menggunakan pendekatan ilmu sosial dan ekonomi (Pranoto, 2010). Pendekatan ini membantu penulis dalam mendeskripsikan tentang perkembangan pelabuhan dan dampaknya terhadap kehidupan sosial ekonomi nelayan. Pada tahap kritik sumber tersebut, penelitian ini menekankan pada otentisitas dan kredibilitas sumber. Kemudian pada tahap ketiga, kajian ini juga menuntut adanya kecermatan dan objektivitas dalam menginterpretasikan sumber. Selanjutnya pada tahap terakhir yakni historiografi, kajian ini dapat ditulis dengan sistematis dan terstruktur dengan pembatasan pada lingkup spasial dan temporal yang jelas.

\section{Letak Geografis Pelabuhan Perikanan Prigi}

Kabupaten Trenggalek terletak di Provinsi Jawa Timur. Kabupaten ini terletak di antara koordinat $111^{\circ} 24^{\prime}$ sampai dengan $112^{\circ} 11^{\prime}$ BT dan $7^{\circ} 63^{\prime}$ sampai dengan 8 '34' LS. Kabupaten Trenggalek di bagian utara berbatasan dengan wilayah Kabupaten Tulungagung dan Ponorogo, di bagian timur dengan Kabupaten Tulungagung, di bagian barat dengan Kabupaten Ponorogo dan Pacitan, sedangkan di bagian selatan berbatasan dengan Samudera Hindia (BPS Kabupaten Trenggalek, 2000). Sementara itu, luas wilayah Kabupaten Trenggalek adalah 120.532 .950 ha, 
terdiri atas 60\% pegunungan dan $40 \%$ dataran rendah. (Dinas Kelautan dan Perikanan Kabupaten Trenggalek, 2002, p. 2). Kabupaten Trenggalek memiliki tiga teluk, yakni Teluk Prigi, Teluk Munjungan, dan Teluk Panggul. Dari ketiga teluk tersebut, Teluk Prigi merupakan teluk yang paling aman dijadikan tempat kapalkapal bersandar dari terjangan ombak Samudera Hindia. Kondisi Teluk Prigi merupakan daerah perairan yang terlindung dengan kedalaman rata-rata 9-35 meter. Produktivitas di Teluk Prigi cukup tinggi. Hal itu karena jumlah plankton sebagai makanan bagi ikan-ikan pelagis yang pola hidupnya bergerombol cukup banyak. Teluk Prigi juga merupakan daerah perikanan penghasil ikan-ikan pelagis kecil $(56,8 \%)$ yang potensial dan dapat dimanfaatkan sebagai umpan ikan hidup, seperti ikan-ikan lemuru, layang, tembang, dan slengseng (Departemen Pertanian Direktorat Jenderal Perikanan, 1994, p. 1). Selain itu, Teluk Prigi juga merupakan teluk paling ramai karena terdapat Pelabuhan Perikanan Prigi.

Pelabuhan Perikanan Prigi yang terletak pada posisi $111^{\circ} 43^{\prime} 38^{\prime \prime}$ BT dan $8^{c}$

17'43" LS dibangun di atas tanah seluas 5,2 ha di Desa Tasikmadu Kecamatan Watulimo. Topografi Kecamatan Watulimo umumnya dataran tinggi mencapai ketinggian sampai dengan 400 meter di atas permukaan air laut. Kecamatan Watulimo di bagian selatan merupakan daerah potensi perikanan yang selama ini belum dieksploitasi secara intensif, sedangkan di bagian lain merupakan daerah perkebunan, kehutanan, dan wisata (Departemen Pertanian Direktorat Jenderal Perikanan, 1983, pp. 3-4).

\section{Keadaan Sosial-Ekonomi-Budaya Masyarakat Desa Tasikmadu}

Sumber-sumber ekonomi yang diakses oleh masyarakat Desa Tasikmadu di Teluk Prigi adalah memanfaatkan sumber daya perikanan di kawasan teluk dan sumber daya hutan. Pemanfaatan sumber daya perikanan yang semula hanya diakses oleh nelayan pancing, kemudian di 1950-an dapat diakses dengan alat tangkap jaring tarik. Pada 1970-an, sumber-sumber ekonomi ditandai oleh semakin bertambahnya alat tangkap berskala besar, seperti payang, purse seine, dan gill net. Berkembangnya sektor perikanan juga telah menjadi faktor penarik bagi nelayan dari Pasuruan untuk mencari peluang pekerjaan ke Prigi. Pada 1990-an, struktur sosial ditandai dengan masuknya sistem pengolahan ikan di Desa Tasikmadu. Hal ini berdampak terhadap sistem pemanfaatan sumberdaya pesisir. Pada masa ini, komoditas ikan layur juga melimpah dan menjadi komoditi ekspor. Nelayan pancing meningkatkan daya tangkapnya dengan meningkatkan ukuran perahu dan mengganti daya dayung dengan motor tempel (Susilo, 2010).

Masyarakat Desa Tasikmadu tidak hanya mencari nafkah dari sektor perikanan saja, melainkan juga berladang dan menjadi petani jika musim tani tiba (Wawancara dengan Bapak Hartono, 19 Oktober 2016). Pada umumnya, masyarakat Desa Tasikmadu masih mempunyai kepercayaan yang kuat bahwa laut memiliki kekuatan magis, sehingga perlu perlakuan khusus dalam melakukan aktivitas penangkapan ikan agar keselamatan hasil tangkapan semakin terjamin. Berbagai aktivitas kehidupan yang bertumpu pada sektor kelautan berbasis agraris sesungguhnya merupakan perwujudan tradisi dan budaya masyarakat pesisir Selatan Jawa (Wawancara dengan Suminto, 14 Maret 2017).

Masyarakat pesisir selatan bergantung pada sektor kelautan meskipun tidak meninggalkan basis agraris. Keengganan masyarakat Pesisir Selatan yang tidak memanfaatkan potensi laut rupanya dipengaruhi oleh nilai budaya. Potensi laut yang begitu lama tidak disentuh rupanya karena mitos Nyi Roro Kidul yang meminta kekuasaan Raja Mataram agar rakyatnya tidak mengeksploitasi Laut Selatan (Zuhdi, 2014, p. 105). Masyarakat nelayan dan petani setiap bulan Selo dalam penanggalan Jawa mengadakan tradisi sedekah laut. Sedekah laut di Teluk Prigi dinamakan Larung Sembonyo. Tradisi ini dilakukan dalam rangka memeringati 
pembukaan kawasan Desa Tasikmadu oleh Raden Tumenggung Yudho Negoro (Wawancara dengan Bambang Supiyat, 30 April 2017).

\section{Perkembangan Pelabuhan Perikanan Prigi 1978-2004}

Tahun 1977-1978 adalah masa ketika Pelabuhan Perikanan Prigi sedang dalam tahap proyek pembangunan pelabuhan. Pada 1978, pembangunan PPP Prigi mulai dilaksanakan di bawah Dinas Perikanan Provinsi Jawa Timur. Pembangunan PPP ini selesai pada bulan April 1983 (Wawancara dengan Bapak Hartono, 19 Oktober 2016). Lembaga yang terkait di pelabuhan yakni KUD Mina Tani Sempurna, proyek pemasaran Ikan basah, koperasi pegawai, kesyahbandaran, Perum Prasarana Perikanan Samudera Cabang Prigi, Dinas Kelautan Kabupaten Trenggalek, dan POLAIR. Untuk mendukung peningkatan nelayan dan produksi ikan, dibangun fasilitas Pelabuhan Perikanan Prigi. Fasilitas ini terdiri atas fasilitas pokok, fasilitas fungsional, dan fasilitas penunjang. Fasilitas pokok di Pelabuhan Perikanan Prigi terdiri atas jetty/dermaga, kolam pelabuhan, tanah, breakwater,dan turap/tanggul.

Fasilitas pokok yang berupa jetty dibangun pada 1983. Jetty memiliki panjang hanya 70 meter dengan lebar 4 meter (Departemen Pertanian Direktorat Jenderal Perikanan, 1983, p. 38). Sampai dengan tahun 2000, jetty masih belum dapat dioperasionalkan secara maksimal dan dalam kondisi rusak (Departemen Pertanian Direktorat Jenderal Perikanan, 2000, p. 27). Pembangunan kolam pelabuhan dimulai pada 1983 (Departemen Pertanian Direktorat Jenderal Perikanan, 1986, p. 40). Pada 2000 dimulai pembangunan fasilitas pokok break water sepanjang 510,5 m2 dan kolam pelabuhan dengan luas 3,5 ha. Fasilitas ini dibangun di sebelah timur lokasi pelabuhan khusus untuk perahu dan kapal perikanan <30 GT (Departemen Pertanian Direktorat Jenderal Perikanan, 2000, p. 33).

Fasilitas pokok yang berupa tanah atau lahan pelabuhan luasnya 5,2 Ha. Tanah ini diperuntukan bagi areal pembangunan gedung-gedung, jalan dalam lokasi, dan lahan pengeringan ikan. Melalui Daftar Isian Proyek (DIP) 1992/1993 ada penambahan 2,2 Ha diperuntukan bagi pengembangan pelabuhan berupa pembuatan kolam pelabuhan dan pemukiman nelayan (Departemen Pertanian Direktorat Jenderal Perikanan, 1992, p. 7). Pada tahun 1994, luas tanah bertambah menjadi 8,5 Ha. Luas tanah 1,1 ha diperoleh dari asset eks-Proyek Pemasaran Ikan Basah (PPIB) Jawa Timur (Departemen Pertanian Direktorat Jenderal Perikanan, 1994, p. 20). Pada 29 April 2000, pengelolaan aset tanah diserahkan kepada Perum Prasarana Perikanan Samudera (Perum PPS) Cabang Prigi sesuai Berita Acara Serah Terima No. PL.440/137/IV/2000.

TPI diserahkan pengelolaan sepenuhnya kepada KUD Mina Tani Sempurna sejak 1975 (Departemen Pertanian Direktorat Jenderal Perikanan, 1983, p. 35). Pada 2003, TPI di sebelah timur sudah mulai dioperasionalkan baik untuk kegiatan pendaratan ikan maupun pelelangan, terutama jenis ikan layur. Pemungutan retribusi lelang yang sebelumnya dilakukan oleh Koperasi Mina Teluk Prigi (SINATI), pada 2003 retribusi dilakukan oleh Dinas Kelautan dan Perikanan Pemerintah Kabupaten Trenggalek (Departemen Pertanian Direktorat Jenderal Perikanan, 2004, p. 20). Pelelangan ikan di PPN Prigi mengalami peningkatan karena adanya pilot proyek TPI murni. Proyek ini bekerja sama antarinstansi terkait, kerja keras penyelenggara lelang serta kesadaran bakul sebagai pemakai jasa (Departemen Pertanian Direktorat Jenderal Perikanan, 2003). Fasilitas fungsional yang berupa pabrik es dimiliki oleh Perum Prasarana Perikanan Samudera Cabang Prigi. Pabrik es berkapasitas sebesar 20 ton per hari (Departemen Pertanian Direktorat Jenderal Perikanan, 2003, p. 9). Bengkel di Pelabuhan Perikanan Prigi pada 2003 sudah memadai, sedangkan asetnya juga dimiliki oleh Perum Prasarana Perikanan Samudera cabang Prigi (Departemen Pertanian Direktorat Jenderal Perikanan, 2003, p. 10). 
Salah satu fasilitas fungsional yang memberikan kemudahan bagi nelayan adalah penyaluran BBM. Pada 1986, BBM hanya dimanfaatkan untuk operasional genset serta pabrik es. Hal ini disebabkan oleh keterbatasan modal kerja pelabuhan (Departemen Pertanian Direktorat Jenderal Perikanan, 1986, p. 42). Instalasi air tawar telah dibangun pada 1982, tetapi baru dimanfaatkan salah satunya oleh KUD untuk mencuci lantai TPI, keperluan operasional pabrik es, kantor, perumahan di lokasi pelabuhan, dan operasional cold storage (Departemen Pertanian Direktorat Jenderal Perikanan, 1996/1997, p. 24). Nelayan belum memanfaatkan fasilitas ini karena fishing ground dekat dan waktu penangkapan hanya berlangsung lima sampai tujuh jam (Departemen Pertanian Direktorat Jenderal Perikanan, 1986, p. 42). Fasilitas fungsional yang berupa pelayanan bengkel di pelabuhan telah dimanfaatkan nelayan dengan baik (Departemen Pertanian Direktorat Jenderal Perikanan, 1983, p. 35).

Fasilitas penunjang yang dimiliki pelabuhan pada 1982-2004, antara lain: balai pertemuan nelayan, kantor pelabuhan, perumahan dinas, mess operator, pos keamanan, halaman parkir, musholla, dan WC umum. Balai pertemuan nelayan mempunyai luas $200 \mathrm{~m}^{2}$. Balai ini dimanfaatkan sebagai tempat penyuluhan nelayan, pencairan dana oleh KUD Mina Tani Sempurna, dan juga untuk kantor sementara Proyek Pemasaran Ikan Basah (PPIB) Jatim (Departemen Pertanian Direktorat Jenderal Perikanan, 1986, p. 47). Fasilitas penunjang yang berupa kantor memiliki luas $150 \mathrm{~m}^{2}$ (Departemen Pertanian Direktorat Jenderal Perikanan, 1992, p. 11). Pada 2001, kantor mengalami kerusakan akibat bencana banjir. Kantor kemudian direnovasi kembali dengan luas $600 \mathrm{~m}^{2}$ (Departemen Pertanian Direktorat Jenderal Perikanan, 2003, p. 9).

\section{Dampak Perkembangan Pelabuhan Perikanan Prigi terhadap Kehidupan Sosial Ekonomi Nelayan Prigi \\ Dampak Sosial}

Dampak sosial dengan adanya perkembangan pelabuhan perikanan di Desa Tasikmadu bagi nelayan, antara lain meliputi perubahan teknologi penangkapan ikan, perubahan hubungan kerja nelayan, dan perubahan bagi hasil tangkapan. Perubahan teknologi penangkapan ikan dipengaruhi oleh hasil difusi pihak luar (Satria, 2002, p. 8). Perubahan teknologi penangkapan ikan di Prigi dipengaruhi oleh nelayan andon atau nelayan pendatang dari Madura dan Bugis. Budaya mboro (Jawa) atau ngandon (Madura), adalah kebiasaan nelayan dalam melakukan migrasi musiman untuk melakukan penangkapan ikan ke lokasi yang jauh dari tempat tinggalnya. Adanya interaksi nelayan lokal dengan nelayan luar Prigi mendorong terjadinya adaptasi teknologi (Masyhuri, 1996, p. 40). Pada 1976, nelayan andon yang berasal dari Bugis Sulawesi memperkenalkan alat tangkap jenis purse seine (Wawancara dengan Bapak Suminto, 14 April 2017). Pada waktu itu, perahu yang digunakan nelayan purse seine sudah menggunakan motor tempel dengan kapasitas 5-10 GT (Wawancara dengan Bapak Hartono, 14 April 2017).

Berdasar jenis alat tangkap yang digunakan dari 1978 sampai dengan 2004, nelayan Desa Tasikmadu terbagi atas nelayan modern dan nelayan tradisional. Nelayan modern adalah nelayan yang mengoperasikan alat tangkap purse seine, gill net, dan pancing tonda. Adapun armada yang digunakan oleh nelayan modern adalah motor tempel dan kapal motor. Wilayah operasi penangkapan nelayan modern berada pada perairan lepas pantai. Nelayan tradisional merupakan nelayan yang mengoperasikan jenis pukat pantai/jaring tarik dan pancing ulur. Pada 1970an, penangkapan ikan di Teluk Prigi dilakukan di dekat pantai dengan menggunakan alat tangkap tradisonal (Wawancara dengan Bapak Hartono, 19 Oktober 2016). Armada yang digunakan nelayan tradisonal berupa motor tempel, 
serta perahu tanpa motor adalah konting dan gethek. (Departemen Pertanian Direktorat Jenderal Perikanan, 1992, p. 4). Sementara itu, alat tangkap pukat pantai dianggap efektif untuk dioperasikan justru pada saat bukan musim ikan (Departemen Pertanian Direktorat Jenderal Perikanan, 2000, p. 4).

Pada 1980, nelayan tradisional pancing ulur telah menggunakan perahu yang panjangnya 11 meter dan lebarnya 2 meter. Setiap perahu dioperasikan oleh empat orang nelayan. Tiga nelayan bertugas sebagai pandega atau pendayung dan satu orang sebagai juru mudi atau nakhoda. Pada 1980-an, jumlah pekerja bertambah menjadi enam orang, satu orang menjadi mandor dan lima menjadi pendayung (Wawancara dengan Bapak Suminto, 19 Juni 2017). Dalam perkembangannya, sekitar 1982, nelayan mulai menggunakan motor tempel. Pada 1992, motor tempel mulai masif digunakan oleh nelayan. Adapun perahu yang digunakan pada periode ini jukung. Pada 2000, perahu yang digunakan untuk menangkap ikan ukurannya semakin besar dengan panjang 3 meter kali 12 meter (Wawancara dengan Bapak Suraji, 17 Juli 2017).

Armada yang digunakan di Prigi sendiri digolongkan menjadi tiga jenis, yakni kapal motor, motor tempel, dan perahu tanpa motor. Kapal motor adalah kapal yang bagian mesinnya sudah ditanam di dalam kapal. Sementara itu, motor tempel adalah kapal yang sudah menggunakan mesin tetapi mesinnya dapat dibongkar pasang. Motor tempel oleh nelayan Prigi disebut kapal jhonson, yaitu merujuk pada merek motor tempel jhonson. Motor tempel digunakan untuk alat tangkap payang, gill net, prawe, dan jaring tarik. Penggunaan motor tempel mengalami penurunan dari tahun ke tahun disebabkan kerusakan pada motor tempel, selain itu penyebab lainnya yakni singkatnya musim ikan di Perairan Prigi. Perahu tanpa motor digunakan nelayan tradisional seperti nelayan pancing. Pemakaian perahu tanpa motor mengalami penurunan dari tahun ke tahun. Hal ini karena nelayan bergeser ke teknologi yang lebih modern, seperti motor tempel (Wawancara dengan Bapak Hartono, 15 Juli 2017). Berdasar uraian di atas, dapat disimpulkan bahwa motor tempel sudah banyak digunakan nelayan Prigi sejak 1979, yaitu sebanyak 210 unit (Departemen Pertanian Direktorat Jenderal Perikanan, 1982, p. 20)

Perahu tanpa motor adalah perahu yang sama sekali tidak menggunakan mesin (Wawancara dengan Bapak Hartono tanggal 19 Oktober 2016). Perahu jenis ini oleh nelayan disebut dengan perahu konting. Perahu konting merupakan tipe perahu jukung, yaitu tipe perahu kecil, yang dibuat dari sebatang pohon utuh kemudian dibentuk menjadi perahu (Masyhuri, 1996, p. 42). Selain perahu konting, nelayan juga menggunakan perahu gethek. Gethek terbuat dari bambu dengan kapasitas empat orang.

Perkembangan jumlah armada di Pelabuhan Perikanan Prigi mengalami kondisi yang fluktuatif sejak 1978 sampai dengan 2004. Hal ini disebabkan jumlah nelayan andon yang singgah dan pergi ke wilayah Prigi cukup banya, sehingga armada yang tercatat menjadi berkurang. Jika musim ikan, nelayan andon banyak yang mencari ikan di Prigi, begitu pula sebaliknya. Kerusakan armada juga dapat menyebabkan perkembangan jumlah armada. Selain itu, nelayan yang tidak memiliki modal akhirnya tidak dapat mengoperasikan kapalnya, sehingga berdampak pada armada yang secara otomatis berkurang.

Perkembangan pelabuhan berdampak pada perubahan hubungan kerja yang terjadi pada masyarakat nelayan Desa Tasikmadu. Pada 1978 sampai dengan 1980, hubungan kerja di antara mereka masih sederhana. Hubungan kerja hanya terdiri atas nelayan juragan atau pemilik kapal dengan ABK. Hubungan kerja antarnelayan Desa Tasikmadu pada umumnya dilakukan berdasar hubungan tolong-menolong, kekerabatan, dan kepercayaan antara pemilik perahu atau juragan darat dengan 
pekerja (Wawancara dengan Bapak Bambang Supiyat, 19 Juni 2017). Hubungan kerja yang demikian terjadi pada nelayan modern dan nelayan tradisioanal.

Pada 1990 sampai dengan 2001, hubungan kerja pada nelayan purse seine lebih kompleks. Sekali berlayar, kapal purse seine mengangkut sedikitnya 25 orang. Hubungan kerja pada nelayan purse-seine terdiri atas juragan darat (pemilik perahu dan alat tangkap), juragan laut (nakhoda), ABK, buruh pelabuhan (tenaga angkut keranjang ikan dan penunggu keranjang ikan), dan bakul ikan (tengkulak). Hubungan kerja nelayan tradisional seperti pukat pantai yakni juragan darat, ABK, pekerjaan sebagai pengurus kapal yang bertugas mewakili ABK pada saat lelang hasil tangkapan dan buruh penarik jaring (Wawancara dengan Bapak Suminto, 14 Maret 2017).

Pada 2001, hubungan kerja pada nelayan purse seine mengalami kerenggangan. Kerenggangan hubungan kerja antara juragan dengan ABK ini karena adanya persaingan untuk mendapatkan juru mudi yang andal. Juru mudi yang andal merupakan kebanggaan tersendiri bagi nelayan. Juru mudi yang tidak mendapat bonus yang besar, akan berpindah ke juragan lain. Juragan akan mengangkat ABK lain untuk menggantikan juru mudi, misalnya tukang mesin/tukang jhonshon. Renggangnya solidaritas internal komunitas juragan dengan ABK kapal purse seine menyebabkan terjadinya pencurian ikan atau esekan. Tengkulak terus mempermainkan dominasi atas nelayan terutama perihal harga (Siswanto, 2008, pp. 29-30). Esekan yang berorientasi ekonomi bermula seorang ABK sebagai tukang jhonshon di kapal purse seine menemukan kecurangan juragan. Kecurangan tersebut antara lain jumlah bobot ikan hasil tangkapan nelayan. Dalam setiap satu bulan menurut catatan ABK lebih besar daripada catatan juragan, sedangkan juragan berdalih bahwa total biaya operasinal yang jauh lebih besar daripada catatan ABK (Siswanto, 2008, pp. 24). Para ABK meyakini bahwa juragan telah banyak melakukan kecurangan karena bagi hasil tidak sesuai dengan jumlah ikan yang ditangkap, sehingga wajar jika nelayan mengambil ikan dengan istilah esekan (Wawancara dengan Bapak Bambang supiyat, 19 Juni 2017).

Juragan-juragan pemilik perahu dengan sendirinya memiliki posisi yang kuat di kalangan nelayan. Mereka biasanya menguasai penjualan ikan yang mereka hasilkan, lebih-lebih pada saat perdagangan ikan segar meningkat (Masyhuri, 1996:190). Karakteristik seperti ini memengaruhi tingkat pendapatan nelayan, dari yang tidak memperoleh pendapatan sama sekali hingga yang memperoleh penghasilan dalam jumlah besar. Sistem bagi hasil pada nelayan modern jenis purse seine dari tahun 1978-2004 tidak mengalami perubahan. Sistem bagi hasilnya yakni, hasil kotor dipotong biaya operasional menjadi hasil bersih. Hasil bersih, kemudian dibagi tiga. Dua pertiga bagian untuk pemilik kapal atau juragan darat, satu pertiga bagian untuk ABK dan nakhoda. Nahkoda diberi tambahan $10 \%$ dengan hitungan dua pertiga dikali $10 \%$ milik pemilik (Wawancara dengan Bapak Bambang Supiyat, 30 April 2017).

Sistem bagi hasil pada nelayan pukat pantai yakni dua pertiga untuk juragan atau pemilik perahu dan satu perempat untuk ABK. Pada saat di bibir pantai jaring ditarik 20-30 orang. Jika tidak mendapatkan hasil tangkapan, juragan perahu harus tetap membayar penarik jaring. Sistem bagi hasil pada nelayan jaring tarik tidak mengalami perubahan sejak tahun 1978-2004. Tahun 1980-an upah penarik jaring sebesar Rp. 750,00. Uang tersebut bisa ditukar dengan harga bahan pokok keperluan rumah tangga, seperti beras dan lauk pauk. Para penarik jaring selain mendapat upah Rp. 750,00 juga mendapat makan dan minum. Jika tangkapan ikan melimpah dalam satu hari penarik jaring bisa menarik sebanyak dua kali, dan para juragan jaring tarik tidak menambah upah (Wawancara dengan Bapak Bambang Supiyat, 30 April 2017). 
Sistem bagi hasil pada nelayan pancing ulur dengan jumlah nelayan dua sampai tiga orang dalam sekali melaut yakni satu pertiga untuk biaya operasional (membeli es, BBM), dua pertiga untuk ABK (juragan dan nakhoda). Sistem bagi hasil pada jaring payang dan trammel net atau jaring pithil tidak jauh berbeda dari sistem bagi hasil pancing ulur. Sistem bagi hasil nelayan pancing ulur tidak ada perubahan dari 1978-2004 (Wawancara dengan Suraji, 15 Juli 2017).

\section{Dampak Ekonomi}

Kegiatan usaha perikanan tangkap merupakan aktivitas ekonomi yang kompleks karena melibatkan banyak pihak yang saling terkait fungsional dan substansial. Sekurang-kurangnya pihak-pihak tersebut adalah nelayan pemilik perahu (perahu dan alat tangkap), nelayan buruh (pandega), pedagang ikan (bakul), dan pemilik toko, yang menjadi pemasok kebutuhan hidup nelayan atau kebutuhan melaut.

Pada 1982, jumlah nelayan purse seine bertambah. Hal ini karena penggunaan teknologi modern dan pembangunan fasilitas pelabuhan yang menunjang kebutuhan nelayan seperti instalasi BBM, bengkel, dan cold storage (Wawancara dengan Bapak Suraji, 15 Juli 2017). Peningkatan pendapatan nelayan pancing ulur bertambah setelah PPP Prigi dibangun pada 1982. Keberadaan PPP juga dibarengi pembangunan TPI Timur untuk nelayan kecil, sehingga nelayan pancing ulur lebih mudah mendaratkan ikan di TPI Timur Pelabuhan Prigi dan dapat menjual ikan kepada bakul ikan (Wawancara dengan Suraji, 15 Juli 2017). Pada 2001, pendapatan nelayan jaring tarik di PPN Prigi menjadi berkurang karena lokasi penangkapan semakin sempit, dan juragan jaring tarik merasa bahwa tempat mereka digusur oleh teknologi yang lebih modern (Wawancara dengan Suminto, 19 Juni 2017).

Pembangunan Pelabuhan Prigi juga berdampak pada pengusaha pengolahan ikan, salah satunya adalah pemindangan. Pemindangan adalah jenis usaha yang berkembang pesat di Desa Tasikmadu. Usaha pemindangan mulai tumbuh dan berkembang pada 1997. Pada 1990-an, ikan dipasok dari nelayan jaring tarik dan nelayan payang. Pada 1998 pengusaha pemindangan mulai memasok ikan dari Surabaya dan Banyuwangi (Wawancara dengan Lasino, 12 Juli 2017).

Pembangunan cold storage di PPN Prigi pada 2001 menyebabkan pengusaha pengeringan ikan lahannya tergusur dan lebih sempit. Meski demikian, perkembangan pelabuhan perikanan juga telah mendorong perkembangan sentra pengeringan ikan. Sentra pengeringan adalah usaha yang berfokuspada pengolahan ikan menjadi ikan asin dan pakan ikan. Pengeringan ikan yang mulanya hanya berkembang di sekitar Dusun Karanggongso, kemudian berkembang juga di beberapa dusun, yaitu Dusun Bengkorok, Gares, Kebon, dan Duren (Wawancara dengan Moni, 12 Juli 2017).

PPN Prigi telah membawa dampak positif bagi ekonomi masyarakat, terutama dengan kemunculan beberapa usaha pengolahan ikan milik masyarakat Prigi. Ikan yang didapat dari nelayan digunakan dan diolah oleh masyarakat Prigi menjadi ikan pindang, ikan kering, ikan asin, dan ikan asap. Usaha pengolahan ikan tersebut tentu memberikan sumbangan yang besar terhadap kehidupan ekonomi baik nelayan, maupun masyarakat sekitar. Pada 2004, usaha-usaha tersebut berhasil memproduksi ikan segar sebanyak 4.195 ton, ikan pindang 1.749 ton, ikan asap 3.965 ton, dan ikan kering atau ikan asin 7.885 ton (Departemen Pertanian Direktorat Jenderal Perikanan, 2004, p. 20).

Keberadaan Pelabuhan Perikanan Prigi juga memberikan dampak lain dalam kehidupan ekonomi masyarakat Prigi, yaitu semakin memperluas kesempatan dan peluang kerja. Pada 1970-an, kesempatan kerja terbuka untuk dua desa nelayan, yakni Desa Tasikmadu dan Karanggongso. Pada 1982, kesempatan kerja ikut bertambah seiring dengan perubahan status pelabuhan menjadi PPP. Kesempatan kerja semakin meluas menjadi lima desa nelayan, yakni Desa Tasikmadu, 
Margomulyo, Prigi, Karanggongso, dan Sawahan (Wawancara dengan Bapak Bambang Supiyat, 19 Juni 2014).

Peluang usaha bagi masyarakat Desa Tasikmadu di bidang perikanan juga terbuka lebar. Pada 1982, di Desa Tasikmadu banyak muncul pengusaha pengeringan ikan. Pada 1997, usaha pemindangan ikan semakin berkembang (Wawancara dengan Bapak Lasino, 12 Juli 2017). Pada 2004, seiring berkembangnya pelabuhan menjadi PPN, banyak perusahaan yang menanamkan modalnya di pelabuhan. Perusahaan tersebut bergerak dalam bidang perikanan seperti PT. Prima Indo Bahari Sentosa dengan usaha cold storage dan pabrik es; PT. Bumi Mina Jaya dengan usaha pabrik tepung ikan; PT. Sumber Pangan Nasional dan PT. Sumber Pangan Nasional dengan usaha cold storage (Departemen Pertanian Direktorat Jenderal Perikanan, 2007, p. 30).

Pembangunan Pelabuhan Prigi disadari atau tidak telah meningkatkan pertumbuhan ekonomi, khususnya bagi masyarakat Prigi. Hal ini ditunjukkan dengan peningkatan penyerapan tenaga kerja sebagai nelayan (Departemen Pertanian Direktorat Jenderal Perikanan, 2005, p. 4). Jumlah nelayan lokal di Prigi mengalami kondisi yang fluktuatif dari tahun ke tahun. Nelayan Prigi dibagi menjadi nelayan lokal dan nelayan andon. Nelayan lokal dibagi kembali menjadi nelayan modern dan nelayan tradisonal. Penggunaan istilah modern dan tradisonal dilihat dari pemakaian alat tangkap. Jumlah nelayan modern dari tahun 1979-1994 terus mengalami peningkatan. Begitu pula nelayan tradisional. Jumlah nelayan lokal terus mengalami kenaikan mulai dari 1987 sampai dengan 1994. Sementara itu, nelayan andon mulai banyak mencari ikan di Teluk Prigi pada 1987. Namun pada 2000, jumlah nelayan andon menurun, dari yang semula 805 menjadi 180. Penurunan tersebut terjadi karena kedatangan mereka dipengaruhi oleh musim ikan. Jumlah tersebut semakin menurun pada 2002 karena konflik yang terjadi antara nelayan andon dengan nelayan lokal (Departemen Pertanian Direktorat Jenderal Perikanan, 1982-2006).

Konflik tersebut terjadi karena nelayan lokal tidak menyukai perilaku nelayan andon dari Madura. Nelayan andon sering kali mengacung-acungkan celurit pada saat berebut wilayah penangakapan ikan. Selain itu, nelayan andon juga diterngarai sering kali membuang hajat di area pemakaman umum. Kejadian-kejadian itu kemudian mengusik nelayan lokal dan memicu terjadinya konflik fisik. Puncak konflik terjadi pada 2002, yaitu ketika terjadi pembakaran satu unit kapal nelayan Madura. Peristiwa tersebut ternyata memberikan efek jera kepada nelayan andon. Mereka kemudian tidak lagi berani mencari ikan di kawasan Prigi (Wawancara Bambang Supiyat, 30 April 2017).

Pada 1999-2004, penyerapan tenaga kerja di Pelabuhan Prigi semakin meningkat. Penyerapan tenaga kerja terdiri atas nelayan, pedagang/pengolah ikan, dan pekerja lainnya. Pedagang/pengolah ikan terdiri atas pedagang ikan basah, pengusaha pemindangan, dan pengusaha pengeringan ikan. Pekerja lainnya terdiri atas buruh pikul ikan, penunggu keranjang, tukang becak, sopir kendaraan dan buruh nelayan, bakul ikan, pengurus kapal, warung makan, usaha perbekalan kapal, dan usaha transportasi.

Jumlah seluruh tenaga kerja yang terserap di PPN Prigi pada 2002 tercatat sebanyak 5.751 orang yang terdiri atas 57 orang pegawai PPN Prigi, enam orang personil perum PPS Prigi, enam orang personil POLAIR, lima orang pegawai Dinas Perikanan Kecamatan, satu orang syahbandar, 19 orang karyawan koperasi SINATI, 23 orang karyawan PT. Prima Indobahari Sentosa, 115 pedagang ikan, 315 tenaga pemikul, 95 tukang becak/sopir, 762 tenaga pengolah ikan, 12 karyawan bank, dan 125 tenaga kerja lainnya (Departemen Pertanian Direktorat Jenderal Perikanan, 2003, p. 46). Sementara itu, penyerapan tenaga kerja di PPN Prigi pada 2003 adalah 4.981 orang yang terdiri atas 57 orang Pegawai PPN Prigi, personil Perum PPS Prigi 6 
orang, 9 orang personil Polair, 23 orang karyawan PT Prima Indobahari Sentosa, 125 pedagang ikan, 139 orang tenaga pemikul, 212 orang tenaga pengolah ikan, dan 85 orang tenaga (Departemen Pertanian Direktorat Jenderal Perikanan, 2004, p. 39). Pembangunan Pelabuhan Prigi berdampak bagi kesempatan kerja masyarakat Desa Tasimadu dan daerah luar wilayah Prigi.

Sentra pemindangan ikan juga membuka kesempatan kerja bagi istri nelayan bekerja sebagai pengrajin reyek untuk mendapat penghasilan tambahan. Reyek merupakan tempat untuk menaruh ikan pindang yang terbuat dari bambu. Bahan baku pembuatan reyek diperoleh dari lahan sendiri. Pada 1987, ada sekitar 50 orang pengrajin reyek dengan upah Rp. 10,00 untuk seratus reyek yang didapat. Pengrajin reyek menjualnya kepada pengepul. Meski upah yang didapat tidak cukup untuk memenuhi kebutuhan, istri nelayan tetap semangat bekerja membantu suaminya dan mengisi kekosongan waktu luang, di samping mengurus rumah tangga (Wawancara dengan Ibu Sutiah, 12 Juli 2017).

\section{Simpulan}

Perkembangan Pelabuhan Perikanan Prigi mulai dari 1978 sampai dengan 2004 didukung oleh faktor geografis, sarana prasarana, dan peningkatan pendapatan pelabuhan. Secara geografis, Prigi merupakan kawasan teluk yang aman bagi kapalkapal nelayan untuk bersandar, mengingat ombak Samudera Hindia yang ganas dapat dipecah oleh keberadaan Teluk Prigi. Faktor lain yang memengaruhi perkembangan pelabuhan adalah sarana prasarana yang dibangun di pelabuhan. Perkembangan pelabuhan dari 1982 sampai dengan 2004 menunjukkan peningkatan yang signifikan, jika dilihat dari aspek fasilitas, jumlah produksi ikan, jumlah perkembangan alat tangkap nelayan yang lebih modern, dan pendapatan hasil pelabuhan.

Perkembangan Pelabuhan Prigi sepanjang 1978 sampai dengan 2004, dari mulai masih menjadi PPP sampai akhirnya menjadi PPN, telah memberikan dampak yang positif terhadap kehidupan sosial ekonomi masyarakat nelayan Desa Tasikmadu, di antaranya adalah kesempatan kerja, penyerapan tenaga kerja, dan peluang usaha yang semakin luas. Beberapa peluang usaha antara lain tercipta setelah berdiri usaha pemindangan ikan. Usaha tersebut kemudian juga memunculkan peluang usaha lain, yaitu pembuatan reyek untuk pindang. Kesempatan kerja di bagian pemindangan ikan dan pengrajin reyek terbuka bagi wanita. Selain mengurus rumah tangga, para istri nelayan juga dapat menambah pemasukan dengan bekerja di pemindangan ikan dan pengrajin reyek, disamping membantu pekerjaan domestik suaminya dengan menjadi buruh jaring tarik. Lahan untuk jaring tarik pada 1980-1990 memang terbilang cukup banyak, yaitu tiga tempat, sehingga dibutuhkan buruh penarik jaring yang juga banyak. Pada akhirnya, para istri nelayan turut aktif menjadi buruh penarik jaring. Kesempatan kerja yang bertambah menjadikan pendapat ekonomi nelayan juga bertambah dan dapat memenuhi kebutuhan sehari hari.

\section{Referensi}

Badan Pusat Statistik, Tenggalek Dalam Angka Tahun 2000.

Departemen Pertanian Direktorat Jenderal Perikanan, Laporan Tahunan Pelabuhan Perikanan Prigi Tahun 1983-2007.

Dinas Kelautan dan Perikanan Kabupaten Trenggalek, Laporan Tahunan Dinas Kelautan dan Perikanan Kabupaten Trenggalek 2002-2003.

Masyhuri. (1995). Menyisir Pantai Utara: Usaha dan perekonomian nelayan di Jawa dan Madura 1850-1940. Yogyakarta: Yayasan Pustaka Nusantama.

Pranoto, W. S. (2010). Teori dan metodologi sejarah. Yogyakarta: Graha Ilmu. 
Pudji, P. Edi, S. Erlinda, I. (2017). Household economic activities of coastal resource users' community in cengkrong coastal area, prigi bay, trenggalek district. Russian Journal of Agricultural and Sociology 2 (62): 91-99. https: / / doi.org/10.18551/ rjoas.2017-02.11.

Ratnawati, S. Sutopo, H. (2013). The development of model empowerment poor society in coastal area through net marketing fishery product in East Java. Academic Research International, 5 (1): 237-243. Retrieved from http: / / www.savap.org.pk/journals / ARInt. / Vol.5(1)/2014(5.1-25).pdf.

Satria, A. (2002). Pengantar sosiologi masyarakat pesisir. Jakarta: PT Pustaka Cidesindo, 2002.

Siswanto, B. (2008). Kemiskinan dan perlawanan kaum nelayan. Malang: Laksbang Meditama, 2008.

Widodo, S. K., (2005). Ikan layang terbang menjulang. Semarang: Badan Penerbit Universitas Diponegoro.

Zuhdi, S. (2014). Nasionalisme laut dan sejarah. Depok: Komunitas Bambu. 